Session 1109

\title{
Classroom Testing of VaNTH Biomechanics Learning Modules
}

\author{
Ronald Barr ${ }^{1}$, Marcus Pandy ${ }^{2}$, Anthony Petrosino ${ }^{3}$, Barbara Austin ${ }^{3}$, and Evan Goldberg ${ }^{1}$ \\ Department of Mechanical Engineering ${ }^{1}$, Department of Biomedical Engineering ${ }^{2}$, and \\ Department of Curriculum and Instruction ${ }^{3}$ \\ The University of Texas at Austin \\ Austin, Texas 78712
}

\begin{abstract}
$\underline{\text { Abstract }}$
This paper presents the methodology and results for the classroom testing of biomechanics learning modules developed as part of the VaNTH educational coalition. The pedagogical framework for these modules is based on the widely publicized book "How People Learn" (HPL). The HPL teaching framework presents the learning material as a series of challenges that are posed through a "Legacy Cycle." Three VANTH modules, covering seven challenges, were tested in an undergraduate Mechanical Engineering course in Fall 2003. The class $(N=32)$ was divided into two groups, control and trial, based on a random assignment. The control group performed the challenge in a traditional way (pencil and paper) while the trial group solved the challenge using the VaNTH material located at a website. For each group, a pre-test, post-test, and affect ranking were administered. The students were also surveyed on the learning effectiveness of the various components of each module. Each group also handed in a homework set for each challenge. The aim of the study was twofold. First, to determine if there was any difference in the educational performance between the trial group versus the control group. Secondly, to determine what parts of each module were most effective and which parts were least effective in student learning, in order to improve each module for future learners.
\end{abstract}

Introduction

The course ME 354M, "Biomechanics of Human Movement," is an undergraduate technical block elective in Mechanical Engineering (ME) that has been offered every year since 1987. During those previous years, the course was taught in a traditional format with chalkboard lectures and overhead transparencies, and with a few paper handouts distributed as needed. There is no required textbook for the course and the primary lecture content has been prepared ad hoc over the years by the first author. The major lecture topics covered in the course have included:

1. Musculoskeletal Physiology and Anthropometrics;

2. Analysis and Simulation of Human Movement;

3. Biomechanical Systems and Control;

4. Computer Graphics Modeling and Simulation in Biomechanics; and

5. Experimental Techniques in Biomechanics.

Proceedings of the 2004 American Society for Engineering Education Annual Conference \& Exposition Copyright (C) 2004, American Society for Engineering Education 
In the Fall 2003 semester, the class was used for testing educational materials as part of a much larger educational research consortium, the NSF-sponsored VaNTH Engineering Research Center for Bioengineering Education. ${ }^{1}$ The objective of the consortium is to develop a new generation of teaching materials and novel approaches for the education of bioengineering students. The pedagogical motivation for the consortium is based on the widely publicized book "How People Learn" (HPL) by Bransford, et al. ${ }^{2}$ The HPL teaching framework presents the learning material as a series of

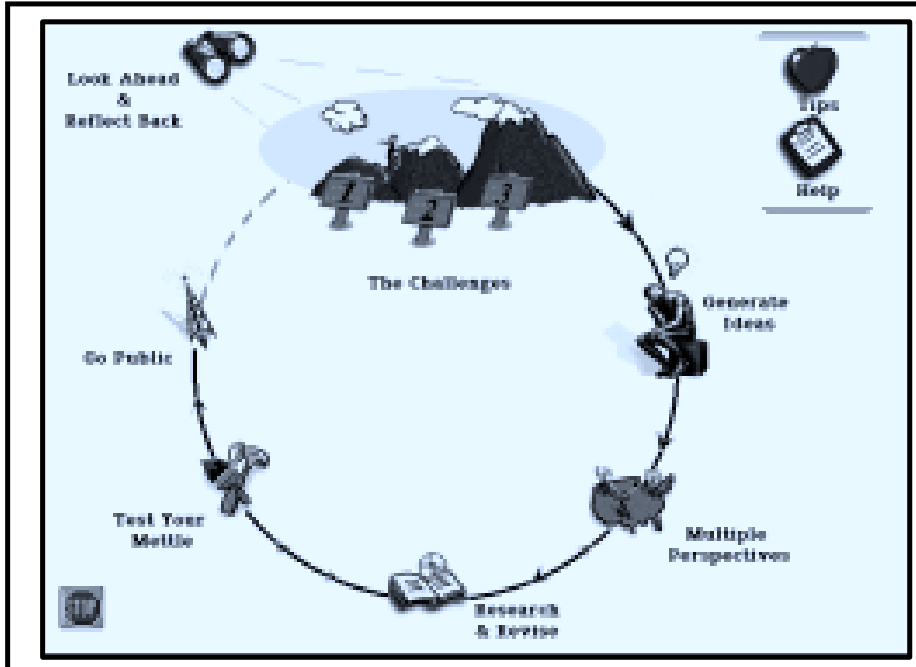

Figure 1: The Legacy Cycle Framework. ${ }^{3}$ challenges that are posed through a Legacy Cycle. ${ }^{3}$ The Legacy Cycle (Figure 1) methodically marches the students through the challenged-based material. Key stages in the Legacy Cycle are: 1 . posing the challenge; 2 . asking students to generate ideas; 3 . providing students with multiple perspectives; 4. making students research and revise; 5. testing students mettle; and 6. having them go public. Concepts learned during each cycle are used as 'legacies' for subsequent cycles.

A total of 32 students were enrolled in the class for the Fall 2003. A request to use students as human research subjects for the course was approved by the University of Texas Institutional Review Board (IRB). Students were asked to sign a human subject consent form and all students graciously obliged. For the testing of the VaNTH learning modules, students were randomly assigned to either a trial group or the control group by drawing the assignment slip from a hat. The trial group used the VaNTH website material for the exercise, and the control group used a hardcopy paper version of the same material. The course instructor recorded the students' names in each group, but also assigned a random two-digit ID number to each student with no correlation between the ID number and the group assignment. This ID number was subsequently used for all data to assure anonymity. Since there were three modules tested, this random assignment procedure was conducted three times during the semester, resulting in Groups $\mathrm{A}$ and $\mathrm{B}, \mathrm{C}$ and $\mathrm{D}$, and $\mathrm{E}$ and $\mathrm{F}$ (see Table 1).

\section{Classroom Testing Methodology}

Three Biomechanics modules, covering seven specific challenges, were tested in this classroom setting. They were:

1. The Iron Cross (IC), one challenge;

2. The Virtual Biomechanics Laboratory (VBL), three challenges; and

3. Jumping Jack (JJ), three challenges.

The same testing methodology was used for each module. First, a general background lecture on the module's topic was given using a Powerpoint slide show prepared by the first author. The 
students were then randomly assigned to their group and were given a pre-test that included a pre-affect survey. Depending on their group assignment, the students showed up at different times for the next lecture assignment. At that lecture, they were presented the modular material, either as a hardcopy paper handout (control group) or as a website location (trial group). As part of their assignment for each module, the students performed a set of homework exercises and also completed a module learning effectiveness survey. After the completion of each module, the students took a post-test and a post-affect survey. Three times during the semester, a student outcomes survey (Pre, Mid, and Post) was administered. All tests and homework exercises were graded by a VaNTH Graduate Teaching Assistant (TA), who used uniform grading rubrics for each case. At the end of the semester, the students also completed a final report that included a matrix that mapped general Biomechanics topics to the modules. Table 1 summarizes this testing methodology.

\begin{tabular}{|c|c|c|c|}
\hline Module Name & $\begin{array}{c}\text { Group } \\
\text { Assignments }\end{array}$ & $\begin{array}{l}\text { Tests and Surveys } \\
\text { Conducted Before }\end{array}$ & $\begin{array}{c}\text { Tests and Surveys Conducted } \\
\text { After }\end{array}$ \\
\hline \multirow{3}{*}{$\begin{array}{l}\text { Iron Cross (IC) } \\
\text { (One challenge) }\end{array}$} & Group A (Control) & \multirow{3}{*}{$\begin{array}{l}\text { - Pre-Test } \\
\text { - Pre-Affect Survey } \\
\text { - Pre-Outcomes Survey }\end{array}$} & \multirow{3}{*}{$\begin{array}{l}\text { - Module Effectiveness Survey } \\
\text { - IC Homework } \\
\text { - Post-Test } \\
\text { - Post-Affect Survey }\end{array}$} \\
\hline & & & \\
\hline & Group B (Trial) & & \\
\hline \multirow{3}{*}{$\begin{array}{c}\text { Virtual } \\
\text { Biomechanics } \\
\text { Laboratory (VBL) } \\
\text { (Three challenges) }\end{array}$} & Group C (Control) & \multirow{3}{*}{$\begin{array}{l}\text { - Pre-Test } \\
\text { - Pre-Affect Survey }\end{array}$} & \multirow{3}{*}{$\begin{array}{l}\text { - Module Effectiveness Survey } \\
\text { - VBL Homework } \\
\text { - Post-Test } \\
\text { - Post-Affect Survey } \\
\text { - Mid-Outcomes Survey }\end{array}$} \\
\hline & & & \\
\hline & Group D (Trial) & & \\
\hline \multirow{2}{*}{$\begin{array}{l}\text { Jumping Jack (JJ) } \\
\text { (Three challenges) }\end{array}$} & Group E (Control) & \multirow{2}{*}{$\begin{array}{l}\text { - Pre-Test } \\
\text { - Pre-Affect Survey }\end{array}$} & \multirow{2}{*}{$\begin{array}{l}\text { - Module Effectiveness Survey } \\
\text { - JJ Homework } \\
\text { - Post-Test } \\
\text { - Post-Affect Survey } \\
\text { - Post-Outcomes Survey } \\
\text { - Topics Matrix }\end{array}$} \\
\hline & Group F (Trial) & & \\
\hline
\end{tabular}

Description of the VaNTH Biomechanics Modules

The objective of the VaNTH coalition is to develop a new set of instructional materials that emphasize the HPL learning theory. As part of the strategy, a modular structure for each identified bioengineering domain was implemented. In the Biomechanics domain, the three modules listed in Table 1 were available for testing in Fall 2003. Each module addresses a specific aspect of the domain's taxonomy (e.g. static equilibrium, projectile dynamics, experimental methods). In order to stimulate student interests in learning the material, a challenged-based approach using the Legacy Cycle was adopted. This approach served as the framework for the web-based challenges used in the ME354M classroom testing. 


\section{The Iron Cross Module}

The Iron Cross (IC) module consists of one challenge: "How much muscle strength is required to sustain the Iron Cross position (Figure 2)". The presentation starts with short testimonials from experts in the field: a surgeon, a mechanical engineer, a sports physical therapist, and a biomedical engineering graduate student. The students also see a video of an amateur gymnast who attempts the Iron Cross maneuver. The students are next asked to formulate a free body diagram (Figure 3) of the forces and moments generated at the shoulder joint. This compels them to think about the mechanics of the position and about the information that is needed to solve the problem. Some anthropometric data, such as the shoulder muscles' origin and insertion points, are presented in the challenge (Figure 4). This leads to the major observation: the IC is a static indeterminate problem due to the multiple muscle actuators that cross the shoulder joint. Thus, the students must make initial assumptions, such as equal stress in all muscles or maximum muscle force activations. They must also calculate the moment arms for all these muscle actuators at the given IC arm angle. They are presented with a generic formulation of the problem (Figure 5) and are asked to solve for the forces in the muscles to maintain this IC position.

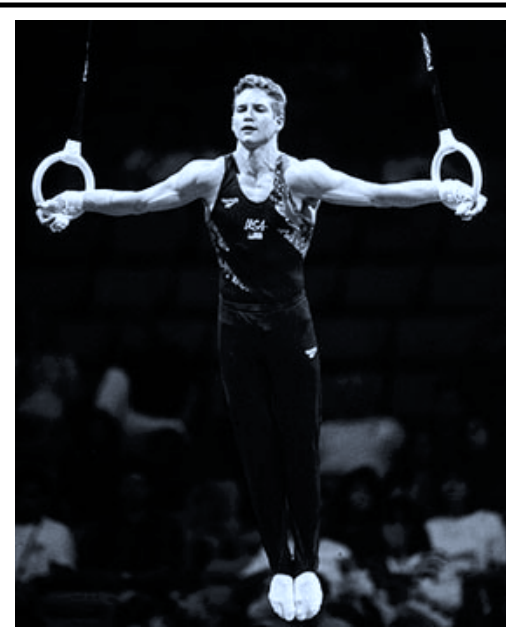

Figure 2: The Iron Cross Position.

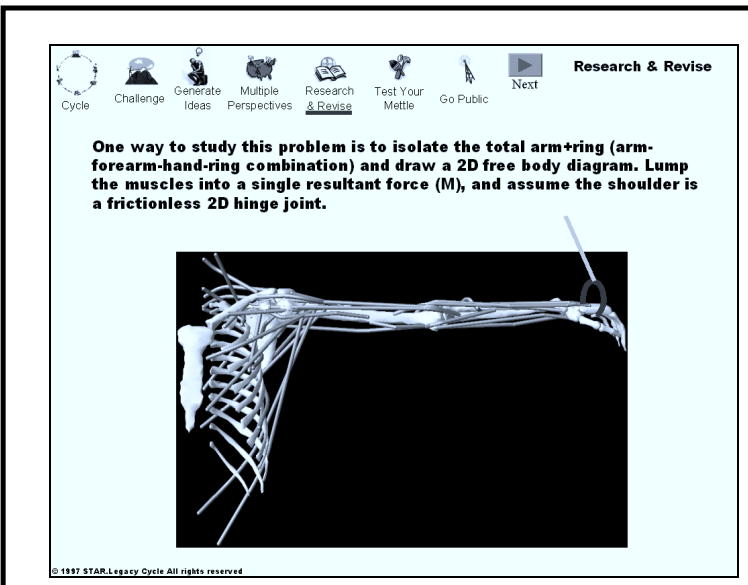

Figure 3: The Free Body Diagram Problem for the Iron Cross.

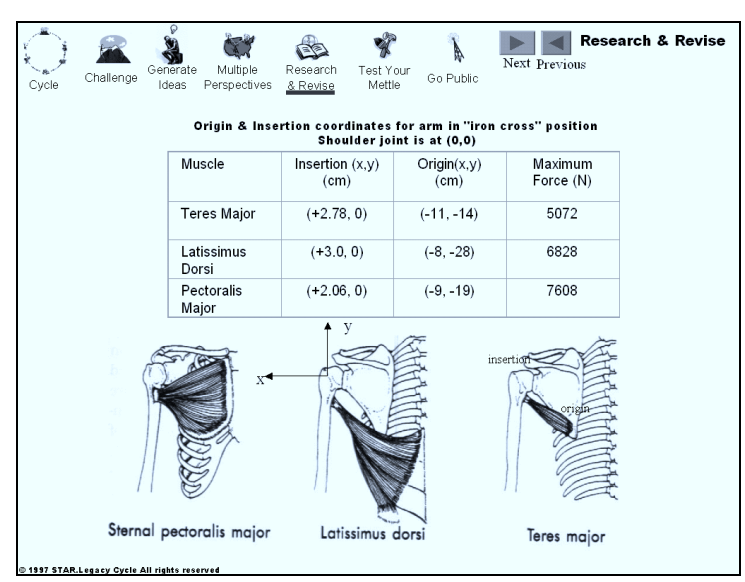

Figure 4: Anthropometric Data About the Shoulder Muscles.

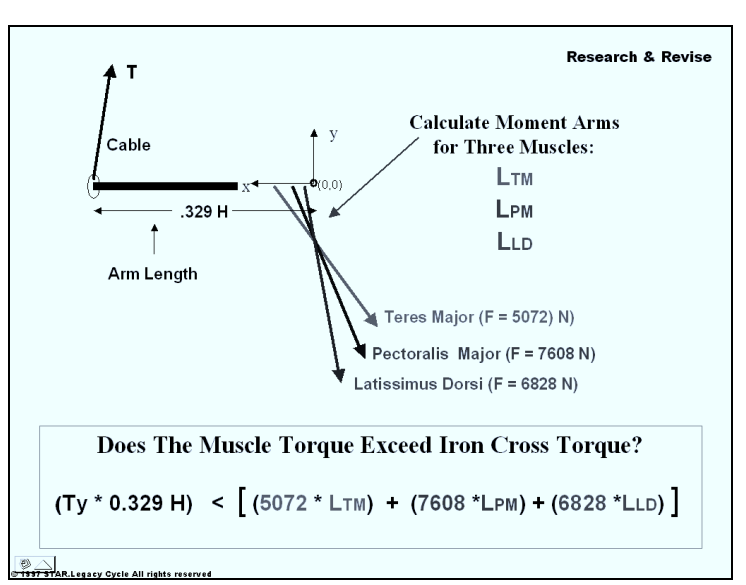

Figure 5: General Formulation of the Iron Cross Problem. 


\section{The Virtual Biomechanics Laboratory Module}

The Virtual Biomechanics Laboratory (VBL) module consists of three challenges, all concerned with experimental observations commonly made in a gait analysis lab. The first VBL challenge is "How does your whole body center of gravity move when you walk?' In order to obtain background information about human gait, the students are presented with several web-embedded movie clips: a stick figure walking (Figure 6), a video-audio of an expert professor (Figure 7), and numerous video-audio clips about data acquisition in a gait lab (Figure 8). Since the main focus of VBL I is center of gravity $(\mathrm{CG})$ calculations, the students receive some background material on multi-segmental CG calculations, starting with a simple static case. They are then presented the main exercise, which is to find the whole body CG using a formula pasted into an Excel

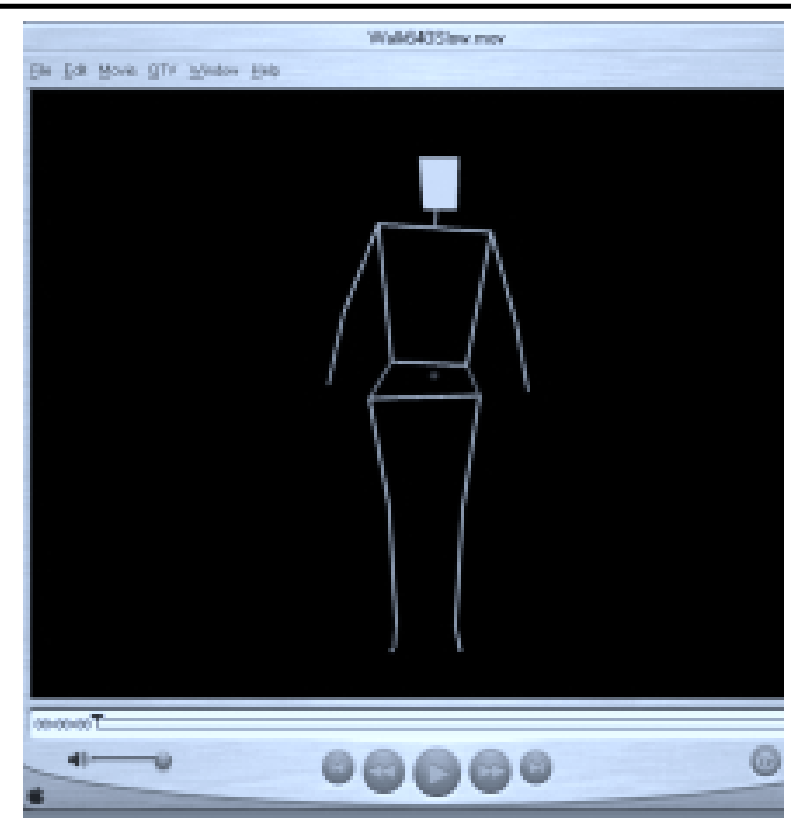

Figure 6: Human Stick Figure Walking Video Clip. spreadsheet. The formula links the various multi-segment data in the columns, and calculates a CG for that case at each time sample point. Then they plot the result of this Excel CG calculation across all samples for the entire gait cycle (see Figure 9) and answer an interesting question about "hitting their head when walking under a door exactly equal to their height."
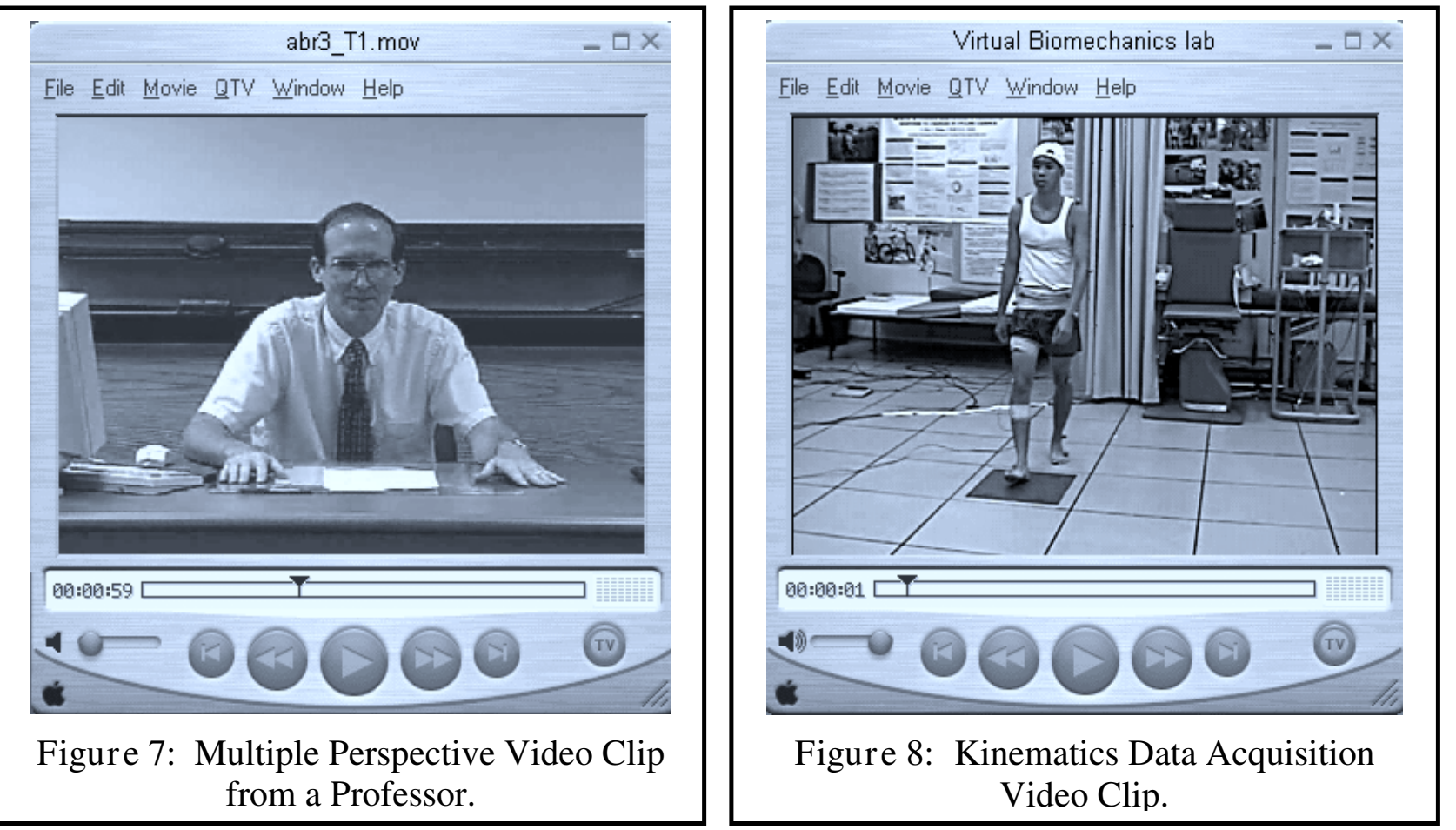

Proceedings of the 2004 American Society for Engineering Education Annual Conference \& Exposition Copyright (C) 2004, American Society for Engineering Education 


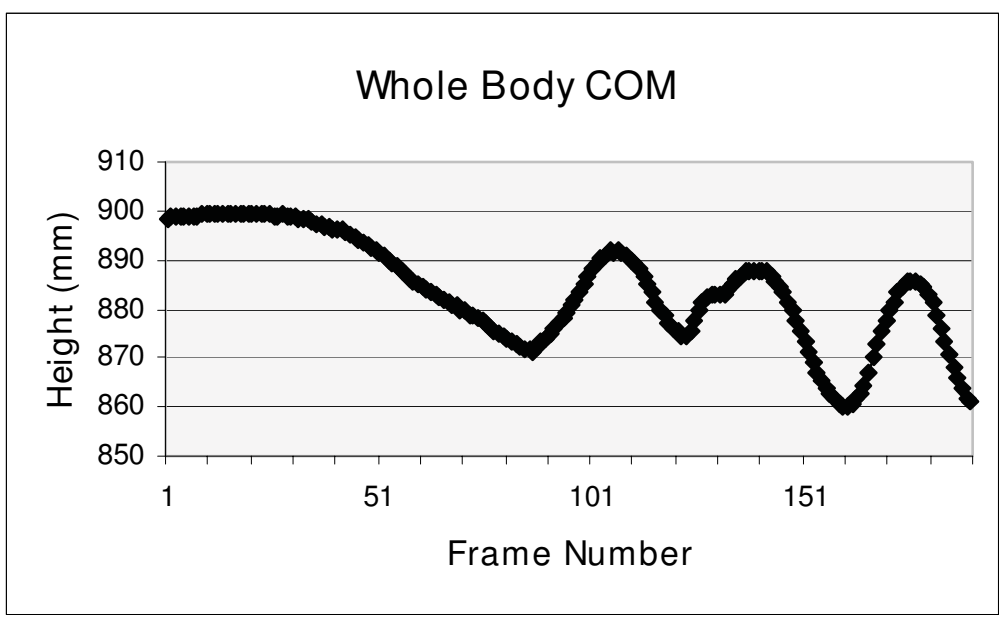

Figure 9: Solution to the Whole Body CG Spreadsheet Exercise.

The second Virtual Biomechanics Laboratory challenge is "What forces do you exert on the ground when you walk?" They are presented with video-audio clips from several experts and are shown a video of someone striking a force plate on the ground (Figure 10). Some background on the gait cycle complements this presentation, since the shape of the force plate curve is highly related to the stages of the gait cycle (Figure 11).

The major exercises for VBL II focus on identification of the various phases of the gait cycle and on interpretation of the ground reaction force (GRF) curve (Figure 12) that is obtained when the subject walks on the force plate. The source of the double hump in the GRF curve poses an interesting question about "whether the subject ever exerts a force on the ground that is less than body weight when walking?" The students then take a spreadsheet file of the ground reaction forces, and use it to calculate and plot (Figure 13) the acceleration of the whole body CG using the formula:

$$
a=[(G R F / m)-g] \text {. }
$$

This then allows them to compare this CG acceleration curve to that from VBL I.

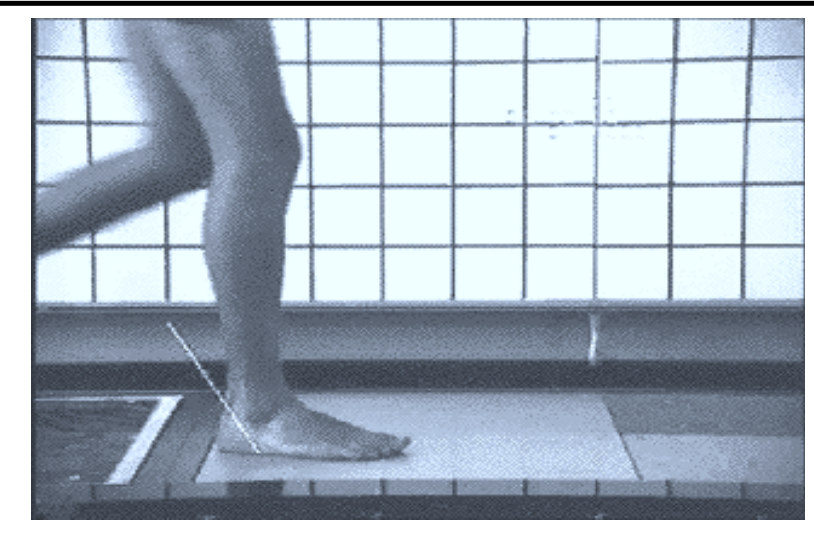

Figure 10: Striking the Force Plate.

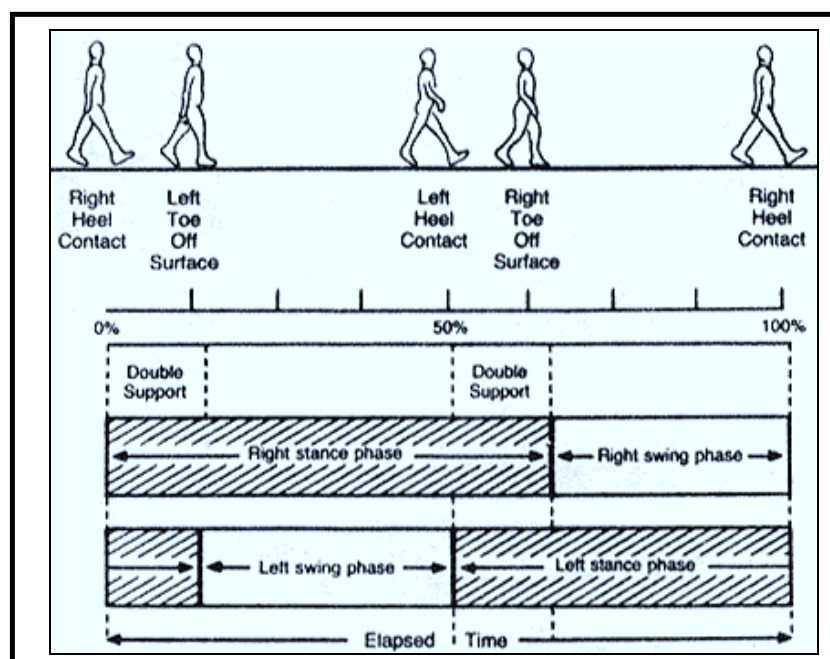

Figure 11: Stages of the Gait Cycle. 
The third Virtual Biomechanics Laboratory is concerned with "How do the leg muscles activate during one complete gait cycle?" The laboratory starts with the anatomy of the major leg muscles that contribute to walking: gluteus maximus, medial and lateral hamstrings, quadriceps, plantar flexors, and dorsal flexors. The students relate which muscles activate during each phase of the gait cycle studied in VBL II.

Next, they are introduced to the electromygraphic (EMG) signal, its electrical origin, and its frequency characteristics. A spreadsheet is supplied with the raw EMG signals gathered in a gait lab for five leg muscles: gluteus maximus, medial hamstring, quadriceps, gastrocnemius, and tibialis anterior. The students plot the raw signals and try to associate the EMG activations with the various phases of the gait cycle, as portrayed in the GRF curve. Next, they process the raw EMG data to get a root mean square (RMS) estimate using a 31-point sliding window formula:

$$
R M S_{i}=\sqrt{\frac{\sum_{\mathrm{n}=-15}^{15}\left(X_{i-n}^{2}\right)}{31}}
$$

Figure 14 shows a typical overplot of the raw EMG and the RMS calculation for the quadriceps muscle.

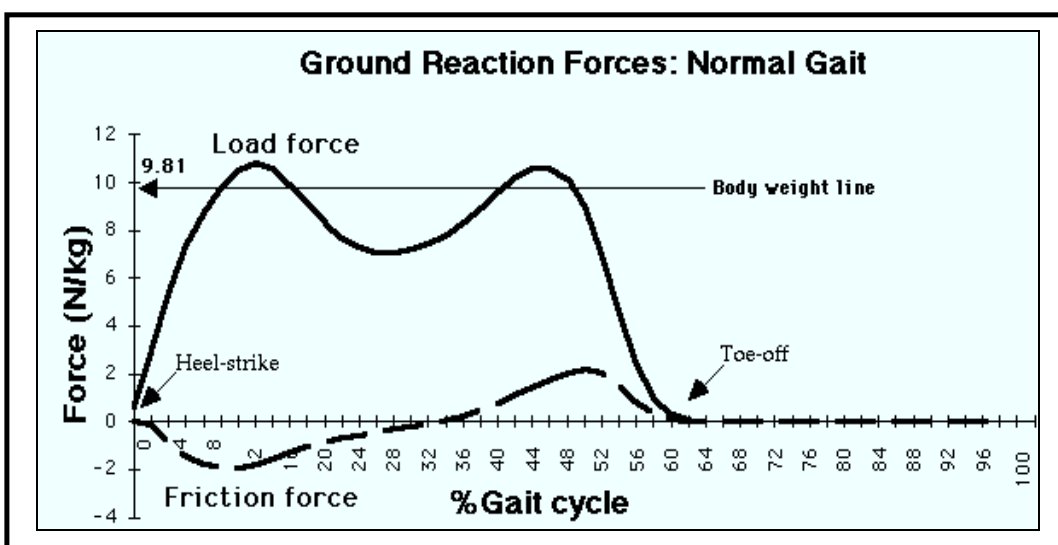

Figure 12: Typical Ground Reaction Force (GRF) Curve. The Vertical Axis is Normalized to Gravity.

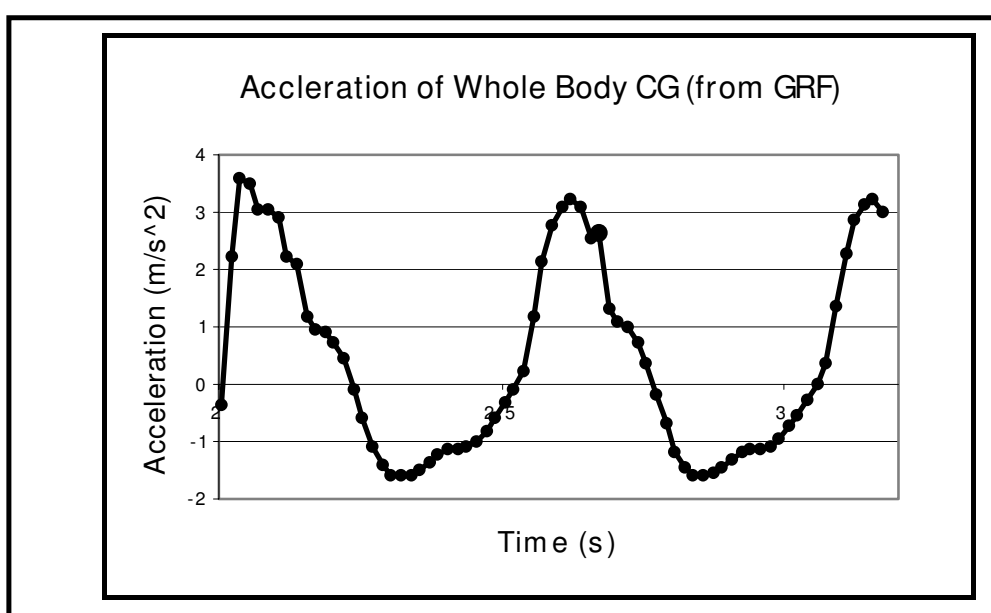

Figure 13: Student Plot of Acceleration of Whole Body CG Obtained from Experimental (GRF) Data.

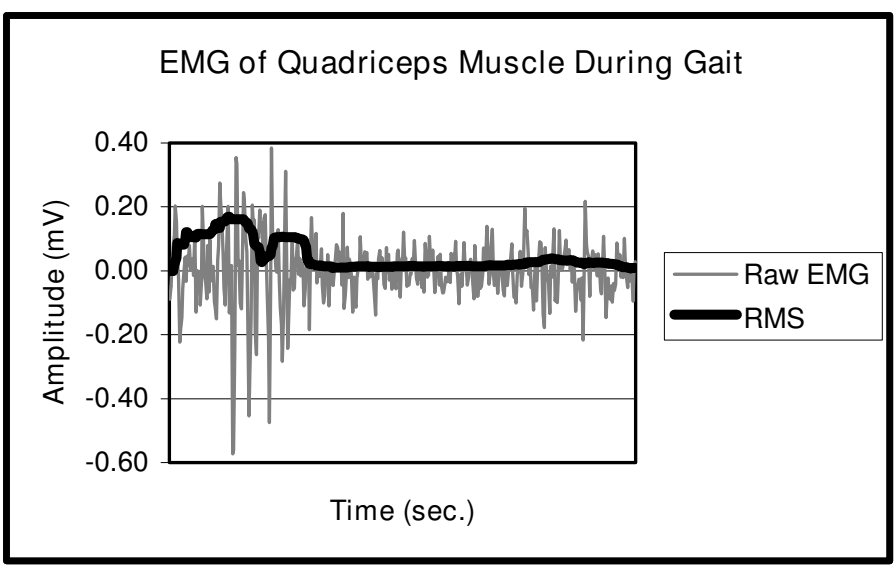

Figure 14: Student Plot of the Raw and RMS Processed EMG for the Quadriceps Muscle. 


\section{The Jumping Jack Module}

The Jumping Jack (JJ) module consists of three challenges, all concerned with the biomechanics of human jumping and the equations of motion for projectile dynamics. The first JJ I challenge is "How high can you jump?" The objective is for the students to compare various ways to calculate a maximum height vertical squat jump (Figure 15). The challenge starts with some video clips of different professors, who talk about the dynamics of jumping. Several on-line documents give background and insight into the problem. A spreadsheet is given with experimental jumping data collected from a human subject. The data contains columns for: ground reaction force, and the vertical position, velocity, and acceleration of the subject's center of mass (COM).

The first jump height calculation is to simply scan the vertical COM position column on the spreadsheet and find the

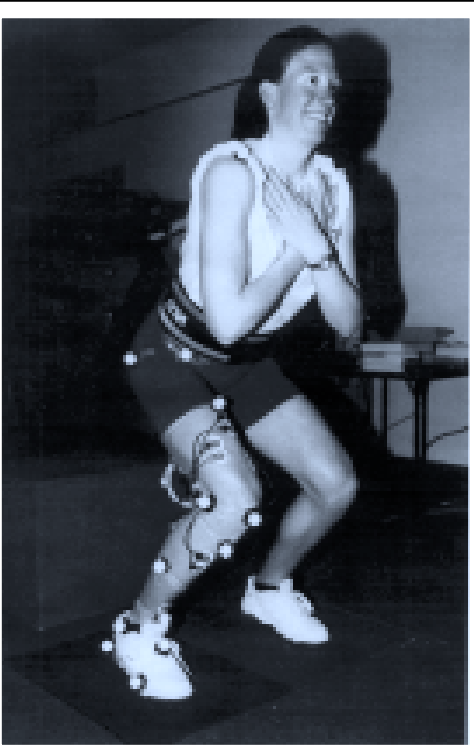

Figure 15: Vertical Squat Jump Experiment. maximum value. The second method is to scan the spreadsheet file and find the velocity $\dot{y}(0)$ of the COM at lift-off, which is when the GRF curve goes to zero. Then they can apply the common projectile equation:

$$
\text { Jheight }=y(0)+\left[\frac{\dot{y}^{2}(0)}{2 g}\right]
$$

A third more elaborate way of calculating the jump height is to use the impulse-momentum method. Here the students first find the COM acceleration during generation of the vertical GRF (Figure 16). They then integrate the acceleration curve to get the lift-off velocity using the formula:

$$
\dot{y}(0)=\int a d t=F_{m}^{F} d t-\int g d t
$$

They then calculate jump height with this new $\dot{y}(0)$ using the earlier projectile equation. This allows the students to compare the accuracy of the various jump height methods used for
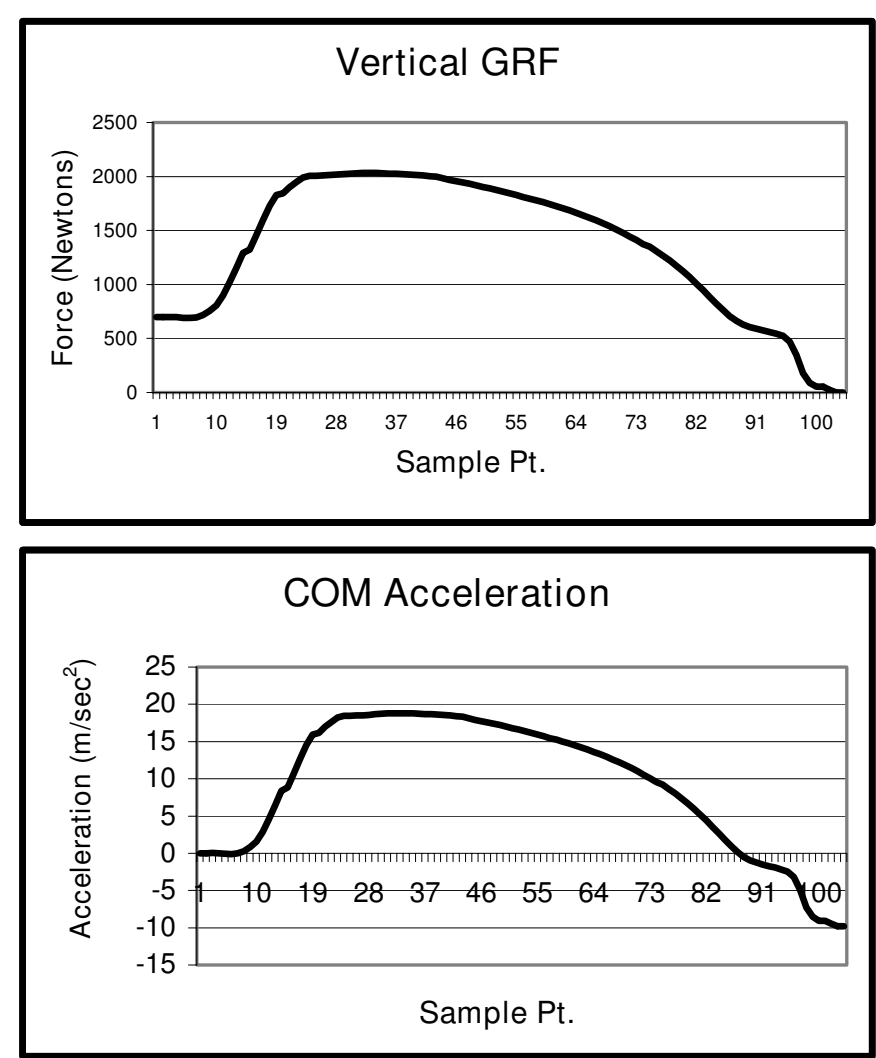

Figure 16: The Vertical GRF and Acceleration Curves for a Squat Jump. this challenge. 
The second JJ II challenge is "What determines jump height?' The students learn about the modeling of muscle systems, and study the generalized muscle force-length and force-velocity curves. Next, they study human jumping using a simple baton (rod) mechanical system (Figure 17). Time histories are provided for the baton's joint angle and angular velocity, and muscle contraction force are given in a spreadsheet. The students derive the equation of motion for the vertical velocity of the baton COM:

$$
\dot{y}=0.25 \cos ()^{\cdot} .
$$

They also calculate the ground reaction force $\mathrm{Fv}$ as a function of the angle :

$$
F v=m g+m(0.25)\left[-\sin ()^{\cdot 2}+\cos ()^{*}\right] \text {. }
$$

When Fv goes to zero, the baton is allowed to fly up and the students can now calculate the maximum height using the angle value determined for fly off.

The second part of JJ II uses a simple optimization routine (Figure 18) to determine the contributions of maximum muscle force and maximum contraction velocity to jump height. For given parameters, the program calculates the optimum muscle activation to maximize the height to which the rod is propelled. They download the program and play around with it, changing the values of maximum force and maximum velocity to see what levels of jump height can be attained by combinations of these parameters.
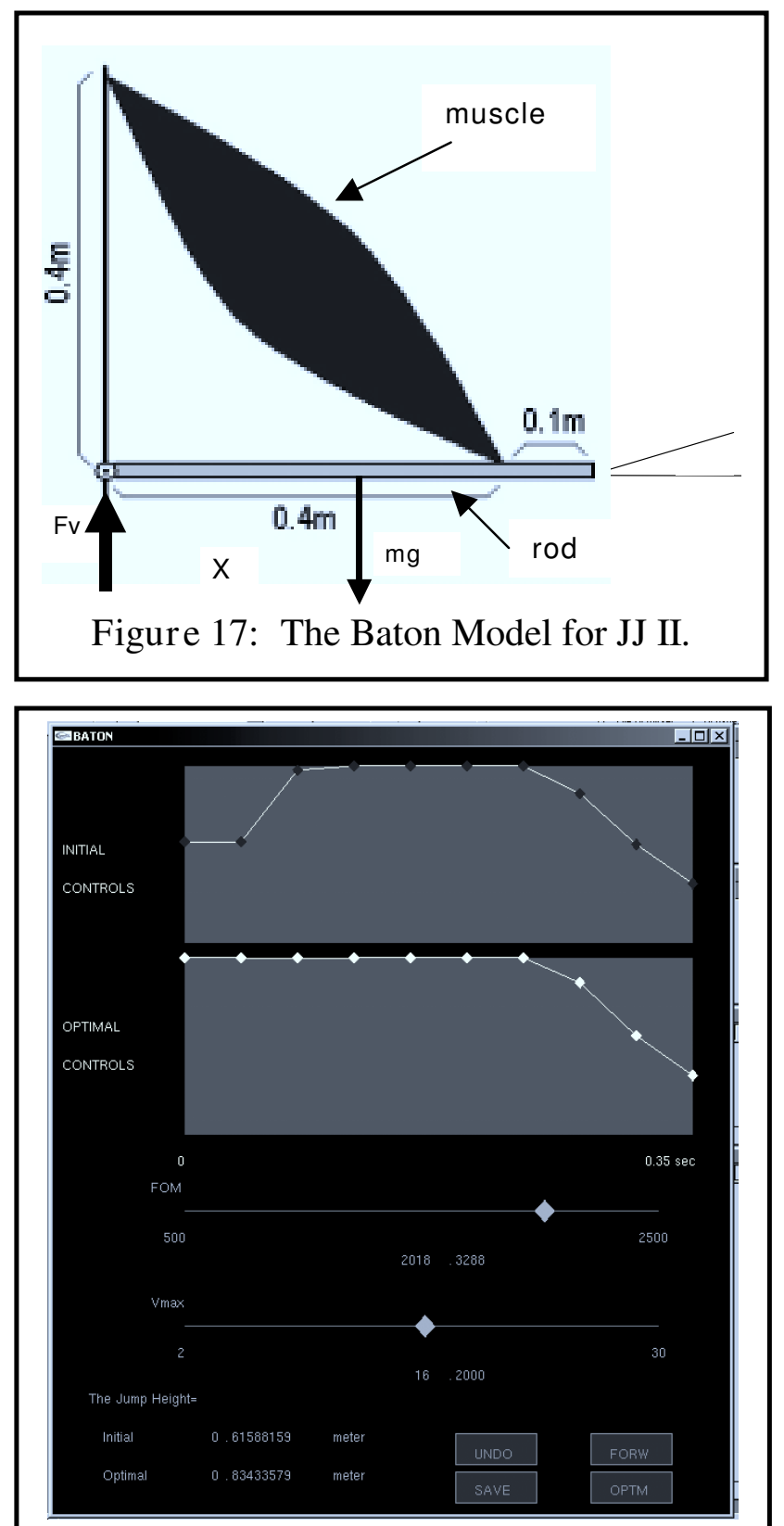

Figure 18: The Baton Optimization Program User Interface for JJ II.

The third Jumping Jack challenge is "What determines who can jump higher?" The students read various papers on what factors result in optimal jumps, including a discussion about gravity and its effect on jumping on the moon. They then download another simulation program that allows them to set the torques histories at three joints: hip, knee, and ankle. They play around with this program interface (Figure 19) and try various values of torques to achieve a maximum jump. They then press the "Jump" button to see how high the model will jump. An accompanying stick figure simulation (Figure 20) lends some computer graphics realism to the simulation. The maximum jump values are then displayed on the interface. After trying various combinations, including altering gravity to jump on the moon, they submit a report. 

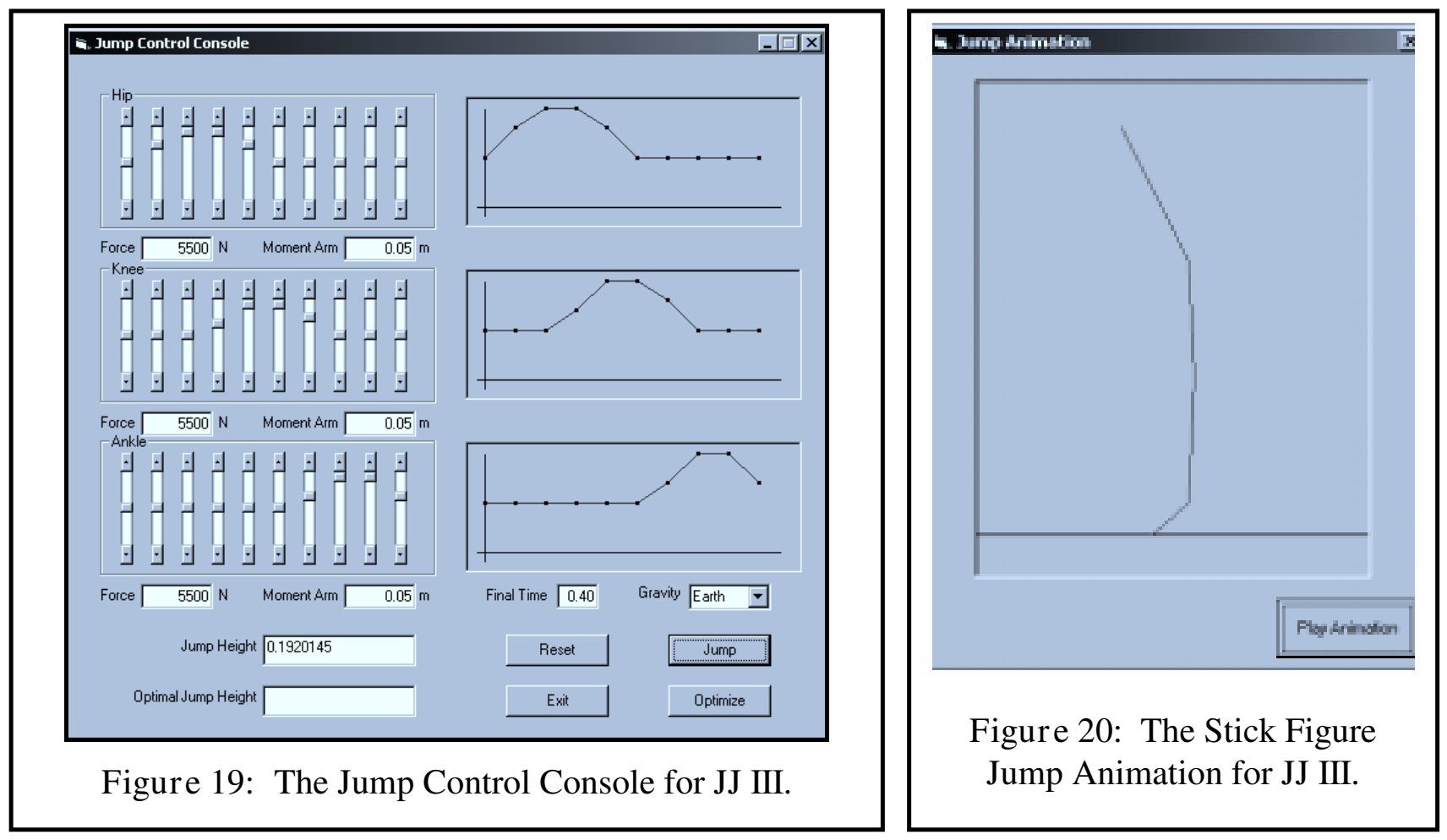

\section{Results of Classroom Testing}

The classroom testing methodology was outlined earlier in Table 1. This methodology included pre- and post-tests, pre- and post-affect surveys, outcomes surveys, module learning effectiveness surveys, homework grading, and a final topics matrix assignment. All data was gathered for both control and trials groups for all three modules. This section will report the raw results of this data gathering.

\section{Pre-Test and Post-Test Results}

Before each module assignment, a short electronic slide lecture was given. The students were randomly assigned to either a control or trial group, and all students then took a pre-test. The pre-tests contain about five to seven questions or problems related to the module topic. Typically, the students were given about 20 minutes to complete this short test. The pre-tests were gathered, were coded by the instructor, and then given to the TA for grading. After the completion of the module, the same test was administered again as a post-test to the students, and the coding/grading process was repeated. Note: The post-test was given after the completion of challenge one for the IC module, and after completion of challenge three for both the VBL and JJ modules.

The results of this pre-post testing phase are shown in the bar graphs in Figures 21 to 23 for the Iron Cross (IC), Virtual Biomechanics Laboratory (VBL), and Jumping Jack (JJ) modules, respectively. The charts are separated into control groups (A, C, and E) and trial groups (B, D, and F) for each module. 

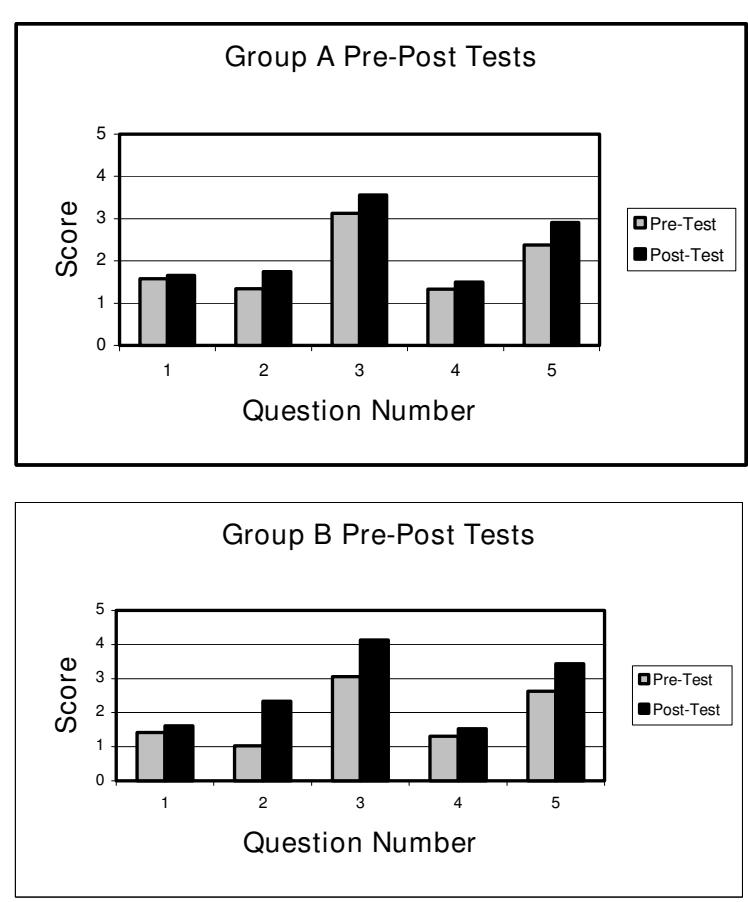

Figure 21: Results of the Pre-Post Testing for the IC Module ( $\mathrm{A}=$ control group, $\mathrm{B}=$ trial group). Dark Bars are for Post-Tests.

The most obvious observation from the bar graph data is that all scores improved in the post-test when compared to the pre-test. This is true for both the control groups and trial groups. This should not be surprising, since the students did learn enough from the modules to improve their testing score on the subject matter. A second comparison is to determine the level of improvement, or gain, when going from the pretest to the post-test. Table 2 depicts these gains in the pre-post test scores. In comparing the gain between the control and trial group, it can be seen that:

1. For the IC module, the trial group B had a higher gain in all five questions.

2. For the VBL module, the control group $\mathrm{C}$ had a higher gain in four of the seven questions.

3. For the JJ module, the control group E had a higher gain in five of the seven questions.

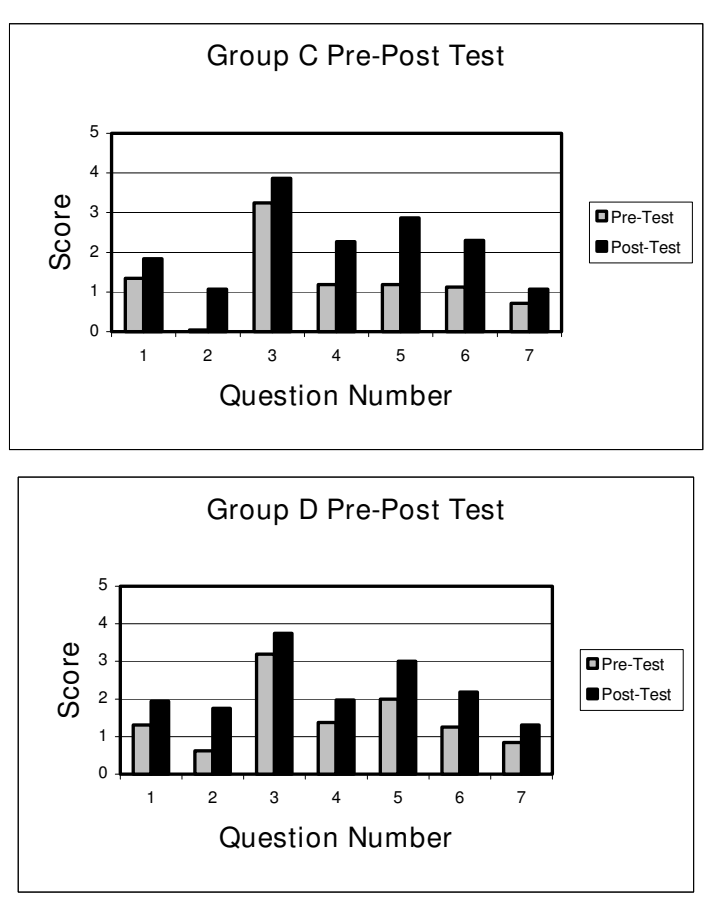

Figure 22: Results of the Pre-Post Testing for the VBL Module $(\mathrm{C}=$ control group, $\mathrm{D}=$ trial group). Dark Bars are for Post-Tests.
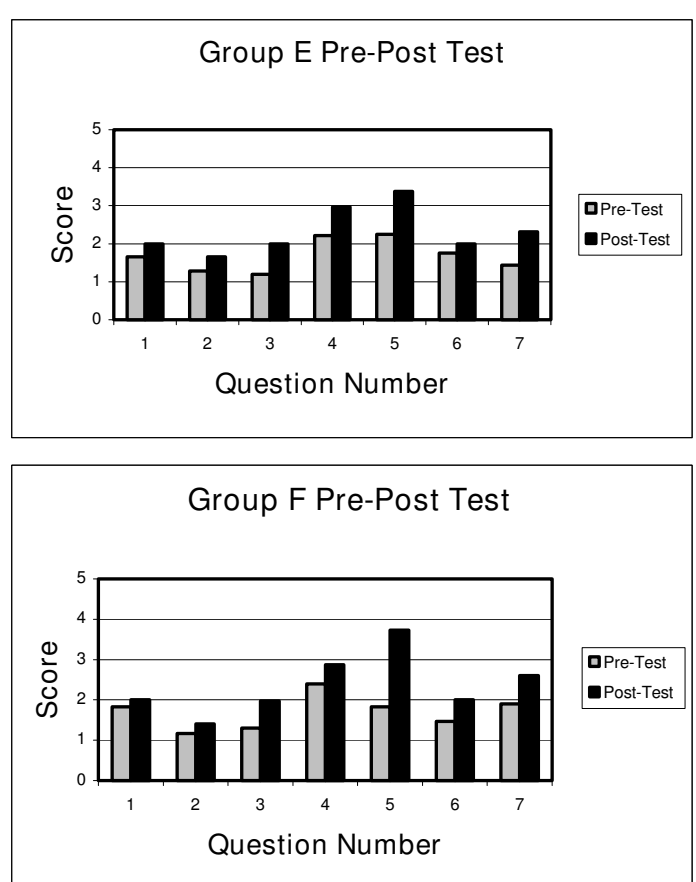

Figure 23: Results of the Pre-Post Testing for the JJ Module $(\mathrm{E}=$ control group, $\mathrm{F}=$ trial group). Dark Bars are for Post-Tests. 
Sometimes a student's learning during an educational experience cannot be totally measured by a test or homework score. The development of appropriate attitudes towards learning can be a significant factor in an educational experience. Our group has developed an affect survey to measure these subjective learning factors. Table 3 lists the seven affective learning factors that students typically would demonstrate during a positive educational experience. This same survey was administered to the students in conjunction with the pre- and post-test tests for all three modules. The students were asked to rank their quality of learning in each of the seven affect questions using a scale of:

1. None

2. Below Average

3. Average

4. Good

5. Exceptional

\begin{tabular}{|c|c|c|}
\hline \multicolumn{3}{|c|}{ Table 2: Gain in Pre- to Post-Test Score } \\
\hline & $\begin{array}{c}\text { Control Group Gain } \\
\text { in Pre-Post Test }\end{array}$ & $\begin{array}{c}\text { Trial Group Gain } \\
\text { in Pre-Post Test }\end{array}$ \\
\hline Question No. & Group A & Group B \\
\hline 1 & 0.08 & $0.19^{*}$ \\
\hline 2 & 0.41 & 1.31 \\
\hline 3 & 0.43 & 1.07 \\
\hline 4 & 0.17 & 0.22 \\
\hline 5 & 0.53 & 0.81 \\
\hline Question No. & Group C & Group D \\
\hline 1 & 0.49 & 0.63 \\
\hline 2 & 1.03 & 1.13 \\
\hline 3 & 0.62 & 0.56 \\
\hline 4 & 1.08 & 0.59 \\
\hline 5 & 1.68 & 1.00 \\
\hline 6 & 1.18 & 0.94 \\
\hline 7 & 0.35 & 0.47 \\
\hline Question No. & Group E & Group F \\
\hline 1 & 0.34 & 0.17 \\
\hline 2 & 0.38 & 0.23 \\
\hline 3 & 0.81 & 0.67 \\
\hline 4 & 0.75 & 0.47 \\
\hline 5 & 1.13 & 1.90 \\
\hline 6 & 0.25 & 0.53 \\
\hline 7 & 0.87 & 0.70 \\
\hline$*$ Bold gains are the higher for each case \\
\hline \multicolumn{2}{|r|}{} \\
\hline
\end{tabular}

Table 3: Affect Survey Used to Measure Quality of Learning in the Course

\begin{tabular}{|l|c|c|c|c|c|}
\hline \multicolumn{1}{|c|}{ Learning Factor } & None & $\begin{array}{c}\text { Below } \\
\text { Aver age }\end{array}$ & Average & Good & Exceptional \\
\hline $\begin{array}{l}\text { 1. I gain factual knowledge (terminology, } \\
\text { classifications, methods, trends). }\end{array}$ & 1 & 2 & 3 & 4 & 5 \\
\hline $\begin{array}{l}\text { 2. I learn conceptual principles, } \\
\text { generalizations, and/or theories. }\end{array}$ & 1 & 2 & 3 & 4 & 5 \\
\hline $\begin{array}{l}\text { 3. I get a chance to talk to other students and } \\
\text { explain my ideas to them. }\end{array}$ & 1 & 2 & 3 & 4 & 5 \\
\hline $\begin{array}{l}\text { 4. I am encouraged to frequently evaluate } \\
\text { and assess my own work. }\end{array}$ & 1 & 2 & 3 & 4 & 5 \\
\hline $\begin{array}{l}\text { 5. I learn to apply course materials to } \\
\text { improve my own thinking, problem } \\
\text { solving, and decision making skills }\end{array}$ & 1 & 2 & 3 & 4 & 5 \\
\hline $\begin{array}{l}\text { 6. I develop specific skills, competencies, } \\
\text { and points of view needed by } \\
\text { professionals in the field. }\end{array}$ & 1 & 2 & 3 & 4 & 5 \\
\hline $\begin{array}{l}\text { 7. I acquire interpersonal skills in working } \\
\text { with others in the class. }\end{array}$ & 1 & 2 & 3 & 4 & 5 \\
\hline
\end{tabular}


The results of these pre-post affect surveys are shown in the bar graphs in Figures 24 to 26 for the Iron Cross (IC), Virtual Biomechanics Laboratory (VBL), and Jumping Jack (JJ) modules, respectively. It can be seen that the overall results present a mixed picture. For example, for the Iron Cross module, the post-affect surveys showed lower rankings when compared to the preaffect surveys for all seven questions in both the control group A and the trial group B. This would suggest that the learning experience of the IC module did not add improvement to any of these learning factors.

On the other hand, for the VBL and JJ modules, some post-affect rankings were higher than their pre-affect counterparts. For example in the VBL module, learning factors $1,2,3$, and 5 all showed improvement in their affect rankings after the module was completed. This was true of both the trial and control affect results. Thus, the students felt that the VBL helped:
a. Gain factual knowledge,
b. Learn conceptual principles,
c. Talk to others about my ideas, and
d. Improve problem solving.

Another observation is whether the post-affect questions showed more improvement in the trial group versus the control group. For example, in the VBL module, group $\mathrm{C}$ (control) showed post-affect improvement in six of the seven learning factors, while group D (trial) showed improvement in five of seven learning factors. However, in the JJ module, group E (control) showed post-affect improvement in only two of the seven learning factors, while group F (trial) showed improvement in five of seven learning factors. This leads to one final display of the affect surveys. Figure 27 shows just the post-affect rankings for the control versus trial groups for the three modules. It can be seen that postaffect rankings were higher for the trial group in the IC and JJ modules, but not for VBL.
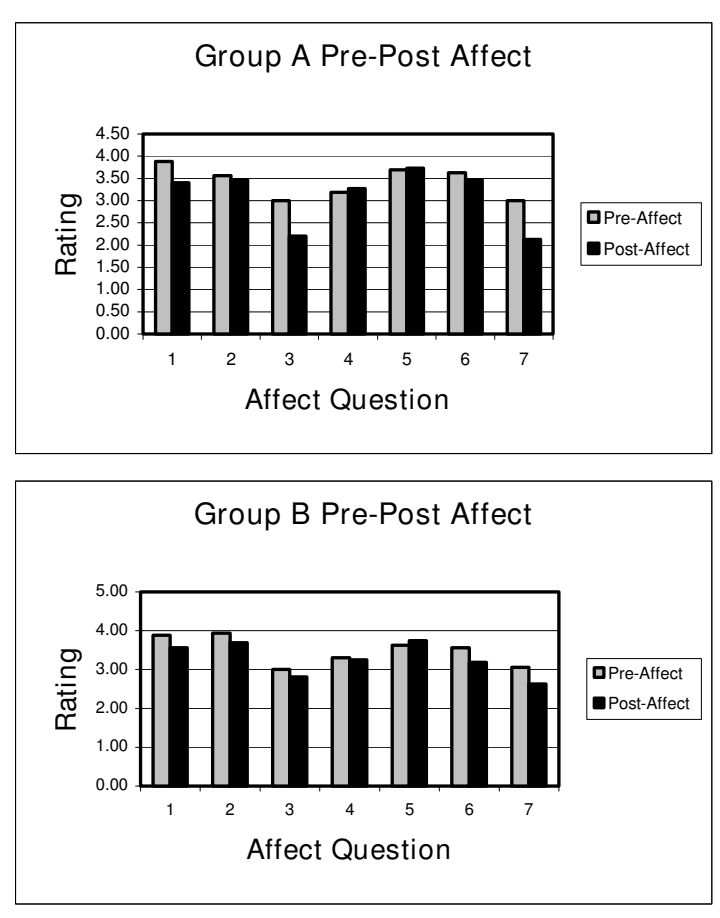

Figure 24: Results of Pre-Post Affect Surveys for the IC Module ( $\mathrm{A}=$ control, $\mathrm{B}=$ trial). Dark Bars are for Post-Affect.
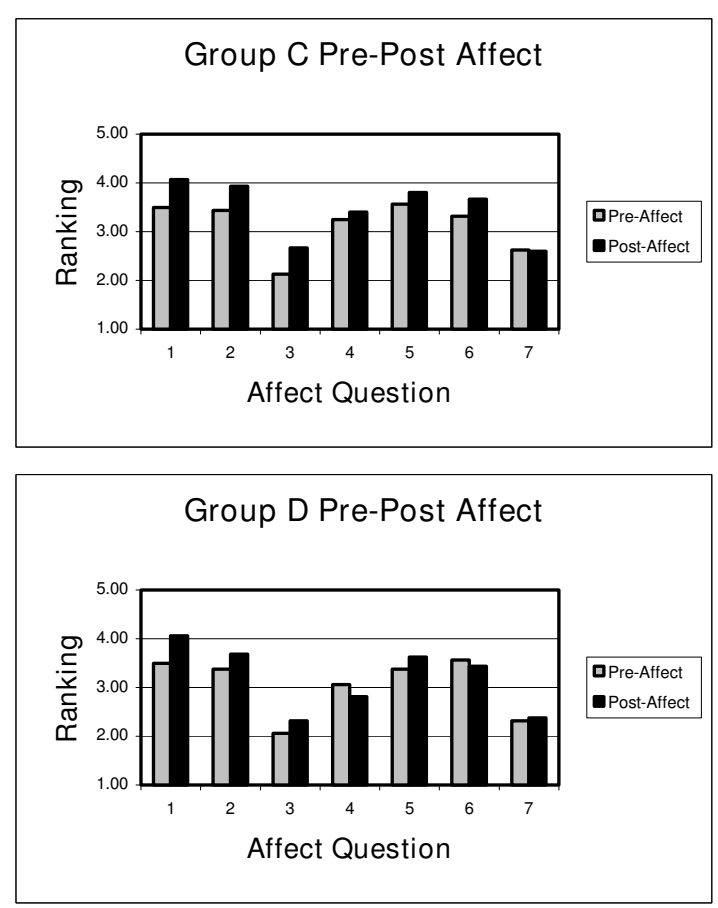

Figure 25: Results of Pre-Post Affect Surveys for the VBL Module $(\mathrm{C}=$ control, $\mathrm{D}$ $=$ trial $)$. Dark Bars are for Post-Affect. 

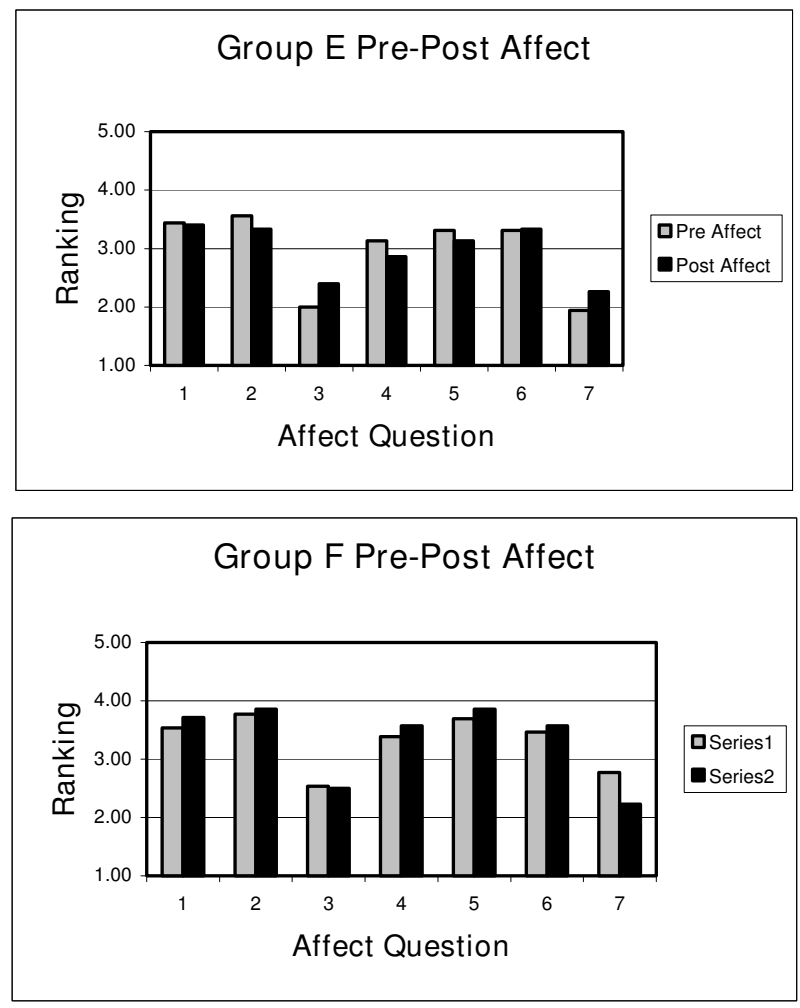

Figure 26: Results of Pre-Post Affect Surveys for the JJ Module $(\mathrm{C}=$ control, $\mathrm{D}=$ trial $)$. Dark Bars are for Post-Affect.
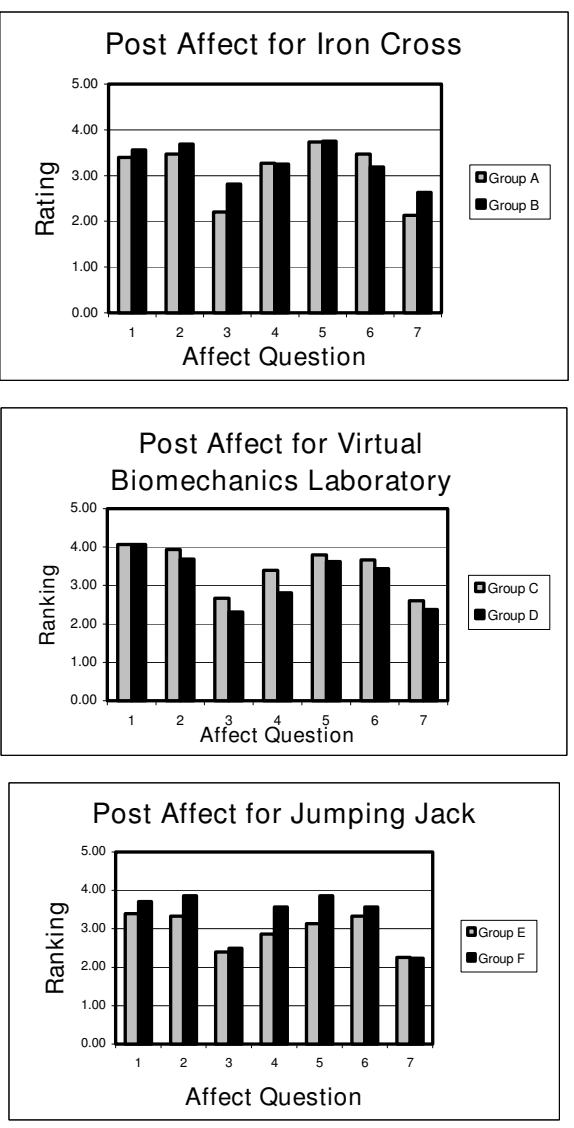

Figure 27: Results of Post Affect Surveys for All Three Modules. Dark Bars are for Trial Groups.

\section{Results of Homework}

The homework assignments typically consisted of between five to seven questions or problems the students needed to solve while completing the module. For the IC module, there was only one challenge, so the homework results in Figure 28 are shown as a function of question/problem number. It can be seen that the homework scores are higher in the trial group B for problems 1,2,3, and 5

For the VBL and JJ modules, the homework problems for each challenge were averaged together and are shown in Figures 29 and 30, respectively. It can be seen that the homework scores for the VBL control group $\mathrm{C}$ were higher for all three challenges, when compared to the averaged homework scores for the trial group D. Likewise, for the JJ module, the control group E homework scores were higher in two of the three challenges, when compared to the averaged homework scores for the trial group F. This suggests that the trial groups' media, an interactive website, did not necessarily lead to higher performance on the material submitted as homework. 


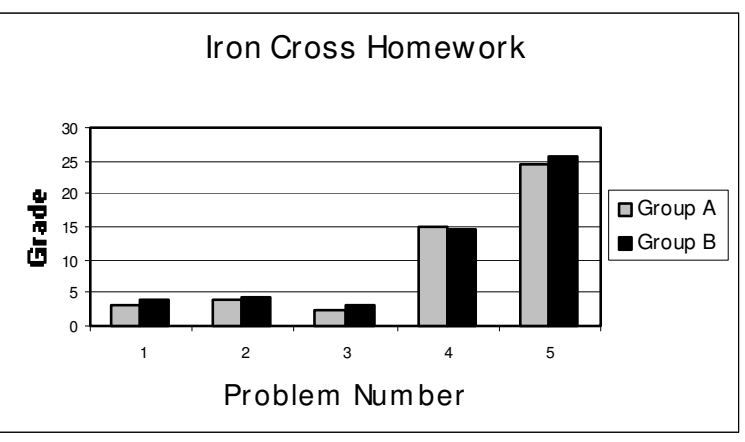

Figure 28: Homework Results for IC. The Dark Bars are for the Trial Group.

\section{Results of Outcomes Surveys}

Student outcomes are defined by the Accreditation Board for Engineering and Technology (ABET) ${ }^{4}$ as the knowledge, skills, abilities, and attitudes that engineering undergraduates should be able to demonstrate at the time of graduation. Table 4 lists the ten program outcomes (PO's) for the Mechanical Engineering Department at the University of Texas at Austin. These ten program outcomes apply to all courses in the ME department.

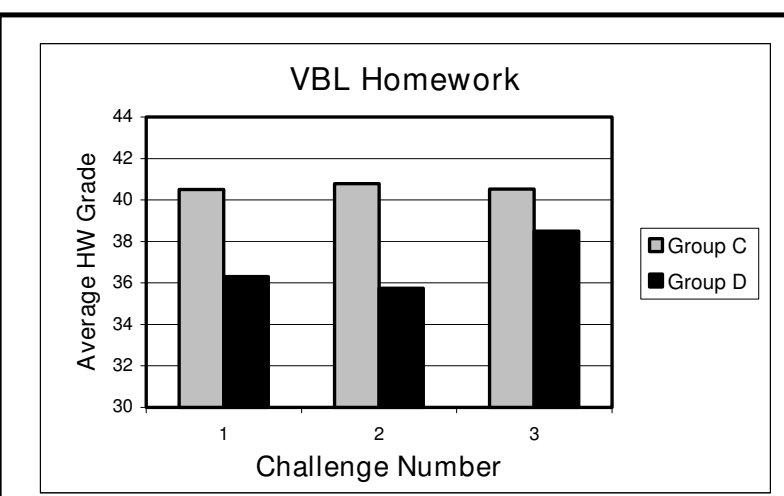

Figure 29: Homework Results for VBL. The Dark Bars are for the Trial Group.

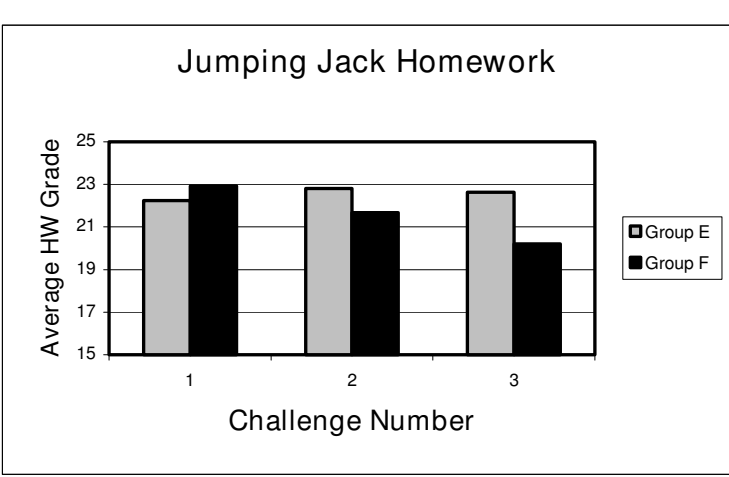

Figure 30: Homework Results for JJ. The Dark Bars are for the Trial Group.

\section{Table 4: The ME Student Program Outcomes.}

1. Knowledge of and ability to apply engineering and science fundamentals to real problems.

2. Ability to solve open-ended problems.

3. Ability to design mechanical components, systems and processes.

4. Ability to setup, conduct and interpret experiments and to present the results in a professional manner.

5. Ability to use modern computer tools in mechanical engineering.

6. Ability to communicate in written, oral and graphical forms.

7. Ability to work in teams and apply interpersonal skills in engineering contexts.

8. Ability and desire to lay a foundation for continued learning beyond the baccalaureate degree.

9. Awareness of professional issues in engineering practice, including ethical responsibility, safety, the creative enterprise, and loyalty and commitment to the profession.

10. Awareness of contemporary issues in engineering practice, including economic, social, political, and environmental issues and global impact. 
In an effort to see how the ME354M course was achieving these departmental-wide outcomes, the students were asked to describe their improvement in each outcome as a result of learning activities provided in the course. This PO survey was conducted three times during the course: Pre, Mid, and Post. The ranking scale was:
1. No skill/ability
2. A little skill/ability
3. Some skill/ability
4. Significant skill/ability
5. Very significant skill/ability

The results of these outcomes surveys are shown in the triple bar graph of Figure 31 . It can be seen that there was improvement in some of the outcomes in going from the Pre- to MidOutcome surveys. In particular, the following outcomes show that improvement:
a. Outcome 2, solve open-ended problems;
b. Outcome 4, conduct experiments and interpret the results;
c. Outcome 5, use of modern computing tools; and
d. Outcome 6, communicate in written, oral, and graphical forms.

Since the Mid-Outcomes survey was administered right after the VBL module, it is not a surprise that experimental, computing, and communication (graphical) outcomes rose noticeably from the Pre-Outcome experiences. Also, the last four outcomes $(7,8,9,10)$ seem to decrease linearly in going from the Pre- to Mid- to Post-Outcomes surveys. These latter outcomes (teamwork, lifelong learning, professional issues, and societal issues) are softer engineering skills that were not addressed in the course, and the student's reflected this fact with their rankings.

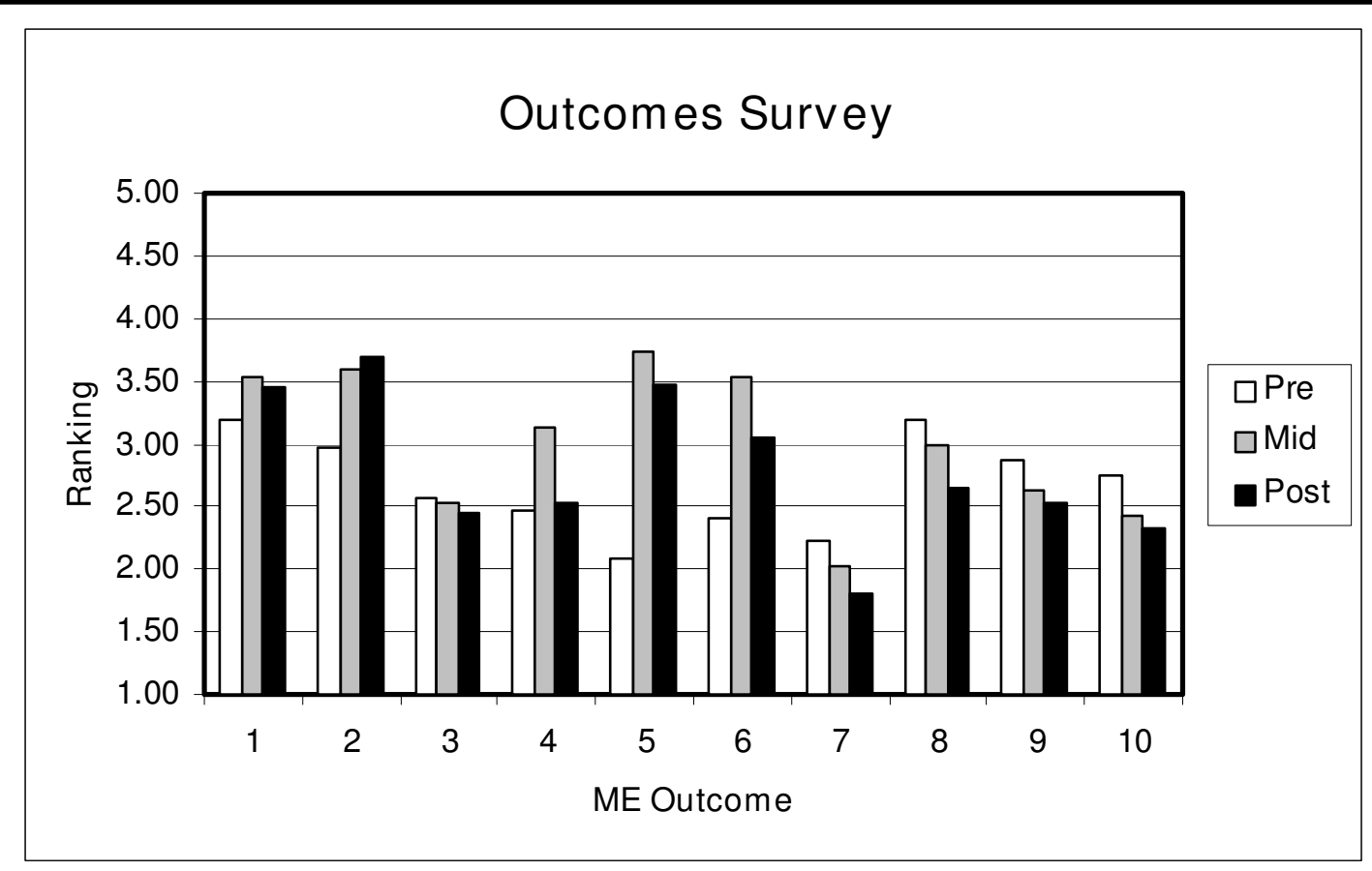

Figure 31: Results of Student Outcomes Survey. ME Outcome Number Refers to Table 4. 


\section{Results of Module Learning Effectiveness Surveys}

One of the major goals of this classroom testing was to determine what aspects of the seven challenges were viewed as acceptable by the students, and which aspects needed improvement. To this end, a module learning effectiveness survey was conducted after the completion of each challenge. In each case, the students were asked to rate each aspect of the challenge for its effectiveness in contributing to the overall learning objectives of the module using the following scale:

\section{Not Effective at All \\ 2 Marginally Effective \\ 3 Somewhat Effective \\ 4 Reasonably Effective \\ 5 Extremely Effective}

Table 5 shows a typical result of this survey for the Virtual Biomechanics Lab I, which was concerned with the whole body center of gravity (CG) challenge. As can be seen, the "Test Your Mettle" exercises received the highest average rankings. These types of results will be helpful as our group works to improve all the modules for the next offering in Fall 2004.

Table 5: Results of the Learning Effectiveness Survey for VBL I

\begin{tabular}{|l|c|}
\hline \multicolumn{1}{|c|}{ Module Aspect } & $\begin{array}{c}\text { Average } \\
\text { Rank }\end{array}$ \\
\hline Look Ahead \& Reflect Back & 2.47 \\
\hline Generate Ideas: Video of Walking Motion & 3.33 \\
\hline Multiple Perspectives: Video of Student & 2.60 \\
\hline Multiple Perspectives: Video of Professor 1 & 3.20 \\
\hline Multiple Perspectives: Video of Professor 2 & 3.47 \\
\hline Multiple Perspectives: Video of Professor 3 & 3.40 \\
\hline Research and Revise: Paper on Center of Mass & 3.40 \\
\hline Research and Revise: Paper on Kinematics & 3.33 \\
\hline Research and Revise: Kinematics Data Collection Video Clips & 3.40 \\
\hline Test Your Mettle 1: Static Center of Mass (COM) Calculation & 4.07 \\
\hline Test Your Mettle 2: Spreadsheet Calculation of Whole Body COM & 3.64 \\
\hline Test Your Mettle 3: Comparison of ASIS Markers to Whole Body COM & 3.62 \\
\hline Test Your Mettle 4: Head Tip Trajectory & 3.46 \\
\hline Test Your Mettle 5: Description of Kinematics Acquisition & 3.29 \\
\hline Go Public: Assemble and Submit Work & 2.45 \\
\hline
\end{tabular}


Biomechanics Topics Matrix

A final survey was conducted at the end of the course. The students were asked to complete a "Biomechanics Topics" matrix. The survey form (Table 6) had a listing in the lefthand column of all pertinent topics that should be taught in an undergraduate Biomechanics course. The students were then asked to check the appropriate cells for each challenge that they felt addressed that particular topic. The results are shown in Table 6, with the total number of mentions (counts) reported by all the students $(\mathrm{N}=32)$ in each cell. Those cells with 20 or more mentions are shaded dark, those with 10 to 19 mentions are shaded light, and those with less than 10 mentions are not shaded. The total counts for each topic are summed in the final column. It can be seen that almost every topic had at least one shaded cell.

\begin{tabular}{|c|c|c|c|c|c|c|c|c|}
\hline Biomechanics Topics & 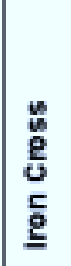 & $\begin{array}{l}\overline{\mathbf{m}} \\
\overline{\mathbf{m}}\end{array}$ & $\begin{array}{l}= \\
\overrightarrow{\text { m }} \\
\text { > }\end{array}$ & $\begin{array}{l}\text { 三 } \\
\text { 畐 } \\
\text { 足 }\end{array}$ & 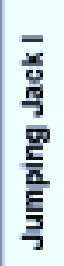 & 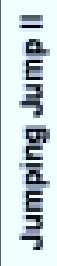 & 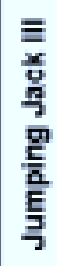 & $\frac{\text { D }}{8}$ \\
\hline Skeletal System & 22 & 12 & 9 & 7 & 6 & 6 & 7 & 69 \\
\hline Muscular System & 28 & 18 & 16 & 26 & 12 & 17 & 17 & 134 \\
\hline Mechanical Properties of Muscle & 22 & 9 & 8 & 15 & 7 & 17 & 19 & 97 \\
\hline Stress and Strain in Muscle & 22 & 6 & 7 & 10 & 4 & 8 & 8 & 65 \\
\hline Classification of Human Movements & 15 & 18 & 24 & 17 & 12 & 9 & 12 & 107 \\
\hline Joint Biomechanics & 19 & 14 & 11 & 7 & 9 & 10 & 11 & 81 \\
\hline Dimensions, Units, Conversions & 21 & 21 & 17 & 17 & 18 & 17 & 15 & 126 \\
\hline Anthropometrics & 14 & 21 & 9 & 8 & 6 & 5 & 7 & 70 \\
\hline Center of Gravity Calculation & 9 & 23 & 19 & 10 & 10 & 4 & 4 & 84 \\
\hline Moment Arm Calculation & 26 & 9 & 6 & 4 & 5 & 9 & 9 & 68 \\
\hline Moment of Inertia Calculation & 4 & 5 & 8 & 5 & 10 & 14 & 4 & 50 \\
\hline Radius of Gyration Calculation & 5 & 4 & 7 & 3 & 3 & 3 & 1 & 26 \\
\hline Free Body Diagrams & 27 & 17 & 11 & 8 & 11 & 12 & 8 & 94 \\
\hline Static Equilibrium Problem & 26 & 7 & 5 & 4 & 2 & 4 & 4 & 52 \\
\hline Linear Kinematics & 2 & 19 & 18 & 9 & 17 & 14 & 10 & 89 \\
\hline Angular Kinematics & 1 & 8 & 6 & 5 & 15 & 22 & 12 & 69 \\
\hline Finite Difference Calculation & 3 & 10 & 14 & 6 & 8 & 6 & 4 & 51 \\
\hline Dynamics of Link Segments & 5 & 18 & 12 & 10 & 9 & 8 & 10 & 72 \\
\hline Reaction Forces & 22 & 13 & 23 & 16 & 17 & 16 & 7 & 114 \\
\hline Torque Summation & 21 & 2 & 3 & 4 & 7 & 14 & 11 & 62 \\
\hline Impulse-Momentum Problem & 1 & 3 & 3 & 3 & 16 & 14 & 8 & 48 \\
\hline First-Order Systems & 8 & 10 & 9 & 4 & 12 & 9 & 3 & 55 \\
\hline Second-Order Systems & 0 & 2 & 3 & 3 & 14 & 14 & 8 & 44 \\
\hline Projectile Dynamics & 1 & 2 & 2 & 1 & 18 & 18 & 11 & 53 \\
\hline Experimental Techniques & 12 & 23 & 23 & 19 & 12 & 10 & 12 & 111 \\
\hline Experimental Equipment & 9 & 24 & 20 & 24 & 13 & 11 & 12 & 121 \\
\hline Electrophysiology and Neural Control & 0 & 3 & 5 & 13 & 7 & 8 & 10 & 46 \\
\hline Computer Graphics Modeling and Simulation & 2 & 11 & 15 & 16 & 17 & 25 & 24 & 110 \\
\hline
\end{tabular}

Proceedings of the 2004 American Society for Engineering Education Annual Conference \& Exposition Copyright (c) 2004, American Society for Engineering Education 


\section{Summary and Conclusions}

This paper presented the methodology and preliminary results for classroom testing of the VaNTH Biomechanics learning modules. A variety of measurements, including tests, surveys, and homework exercises, were implemented in this educational research effort. In order to evaluate the efficacy of this VaNTH approach to instruction, as opposed to a traditional lecture, the class $(\mathrm{N}=32)$ was divided into control and trial groups. In preliminary review of all the testing materials and surveys gathered, some preliminary observations can be made.

1. The results comparing the trial group performance versus the control group are very mixed. In retrospect, there was very little difference between the educational materials delivered to the control group versus the trial group. The only difference was the availability of the video clips on the website, which were in some cases not highly regarded by the students anyway. So it is unclear whether the control group received a traditional approach.

2. The pre-test and post-test methodology worked well. The results are convincing that the students learned the material. Also, measuring the gain from pre- to post-test is a valuable instrument for accessing the level of learning in the treatment.

3. The pre-affect and post-affect surveys are also valuable instruments to measure the subjective aspects of student learning and attitude development in a course. It is interesting to note that some of the highest levels of affect ratings occurred in the post-affect survey after the last JJ module was completed (Figure 27), even though that was the sixth time the students had been asked to complete this same identical form.

4. The results of the homework scores typically favored the control group. One could suspect that the grading key rubrics might be still biased toward a traditional approach. Or perhaps the trial group expected the technology of the website to do more of their work for them?

5. Outcomes testing is a good way to determine where a particular course fits into the overall curriculum or degree plan. Based on the results of this outcomes survey (Figure 31), it appears that the VaNTH Biomechanics modules can contribute to the following ME outcomes:

PO \#2 - Ability to solve open-ended problems;

PO \#4 - Ability to setup, conduct and interpret experiments and to present the results in a professional manner;

$\mathrm{PO} \# 5$ - Ability to use modern computer tools in mechanical engineering; and PO \#6 - Ability to communicate in written, oral and graphical forms.

On the other hand, it is disappointing that PO \# 7 "Ability to work in teams and apply interpersonal skills in engineering contexts" received such a low rating in this course. For sure, teamwork is an issue that must be addressed within the VaNTH coalition.

6. The results of the Biomechanics Topics matrix (Table 6) are pleasing to the authors. It supports the contention that a semester-long, complete Biomechanics course could be taught using these seven challenges as the primary method of educational delivery. For sure, adding one or two more challenges will complete the Biomechanics domain and lead to achievement of the VaNTH goals for the domain. 


\section{References}

1. Harris, T.R., Bransford, J.D. and Brophy, S.P. (2002): Roles for Learning Sciences and Learning Technologies in Biomedical Engineering Education: A Review of Recent Advances. Annual Review of Biomedical Engineering, 4: 29-48.

2. Bransford J.D., Brown A.L., and Cocking R.R., Editors (1999). How People Learn: Brain, Mind, Experience, and School. National Academy Press, Washington, D.C.

3. Schwartz, D. L., Brophy, S., Lin, X., Bransford J. D. (1999). Software for Managing Complex Learning: Examples from an Educational Psychology Course. Educational Technology Research and Development. 47(2), 39 -59.

4. Engineering Accreditation Commission (2002). Criteria for Accrediting Engineering Programs, Accreditation Board for Engineering and Technology (ABET), Baltimore, Maryland.

Acknowledgement

*VaNTH is a bioengineering educational research coalition formed by Vanderbilt, Northwestern, Texas, and Harvard/MIT, and is supported by the Engineering Research Center (ERC) Program of the National Science Foundation (NSF), award number EEC-9876363.

\section{Biosketches}

Dr. Ronald E. Barr is a Professor of Mechanical Engineering at the University of Texas at Austin, where he has taught since 1978. He received both his B.S. and Ph.D. degrees from Marquette University in 1969 and 1975, respectively. His research interests are in Biosignal Analysis, Biomechanics, and Engineering Computer Graphics. Barr is the 1993 recipient of the ASEE Chester F. Carlson Award for innovation in engineering education. Barr is a Fellow of ASEE and a registered Professional Engineer $(\mathrm{PE})$ in the state of Texas.

Dr. Marcus G. Pandy is Professor of Biomedical Engineering at The University of Texas at Austin. Dr. Pandy received a Ph.D. in mechanical engineering from Ohio State University in Columbus (1987). He then completed a two-year post-doctoral fellowship in the Department of Mechanical Engineering at Stanford University. He has been a faculty member at The University of Texas since 1990. Dr. Pandy's research interests are in biomechanics and control of human movement. Much of his research is aimed at using computer models of the musculoskeletal system to study muscle, ligament, and joint function in the normal, injured, and diseased states.

Dr. Anthony J. Petrosino is an Assistant Professor and Learning Scientist in the Department of Curriculum and Instruction at The University of Texas at Austin. He received his M.Ed. from Teachers College, Columbia University (1990) before becoming a member of the Cognition and Technology Group at Vanderbilt. He completed his Ph.D. from Vanderbilt University in 1998. Upon graduation, Dr. Petrosino moved to The University of Wisconsin as a McDonnell Postdoctoral Fellow through the Cognitive Studies in Educational Practice (CSEP) Program. While in Wisconsin, Dr. Petrosino was a contributing member to the National Center for Improving Student Learning and Achievement in Mathematics and Science (NCISLA). His research interests include the design of classroom learning environments, children's experimentation strategies and application of modern learning theory to biomedical engineering education. 